Volume 10, Nomer 03, 2020

\title{
Pengetahuan Ibu Tentang Kartu Menuju Sehat dapat Menstimulus Status Gizi Balita
}

\author{
Sofiya Rahmawati ${ }^{1}$, Diah Ratnawati ${ }^{2}$ \\ ${ }^{1,2}$ Fakultas Ilmu Kesehatan, Universitas Pembangunan Nasional Veteran Jakarta \\ Email: sofiyarahmawati28@gmail.com ${ }^{1}$, ratnawatidiah@yahoo.co.id ${ }^{2}$
}

\begin{abstract}
Abstrak
Pendahuluan: Kartu menuju sehat/KMS berfungsi sebagai media untuk memantau pertumbuhan. Populasi dalam penelitian ini adalah sejumlah ibu balita di wilayah Posyandu Dadali III Kelurahan Tugu, Cimanggis, Depok karena masih banyaknya ibu yang belum memahami keterangan dalam KMS.

Tujuan: Penelitian ini dilakukan untuk mengetahui hubungan pengetahuan ibu tentang kartu menuju sehat dengan status gizi balita.

Metode: Instrumen penelitian ini adalah status gizi dan pengetahuan. Desain penelitian ini adalah dengan menggunakan pendekatan cross-sectional, dimana dengan sampel yang digunakan sebanyak 83 responden. Analisis univariat yang digunakan adalah frekuensi dan proporsi. Analisis bivariate yangdigunakan dalam penelitian ini adalah Uji ChiSquare dengan $p$-value $<0,05$.

Hasil: Hasil penelitian ini didapatkan nilai $p$-value 0,021 artinya ada hubungan antara pengetahuan ibu tentang kartu menuju sehat dengan status gizi balita.

Kesimpulan: Hal ini membuat ibu untuk lebih aktif dalam mencari informasi tentang hal hal yang merupakan interpretasi dari Kartu Menuju Sehat dan juga informasi tentang keadaan status gizi balita.
\end{abstract}

Kata Kunci: balita, kartu menuju sehat, pengetahuan, status gizi

\section{Pendahuluan}

Balita adalah istilah umum bagi anak usia 1-3 tahun (batita) dan anak prasekolah (35 tahun). Saat usia balita, anak masih tergantung penuh kepada orang tua untuk melakukan kegiatan penting, seperti mandi, buang air dan makan. ${ }^{1}$ Masa balita merupakan periode penting dalam proses tumbuh kembang manusia.

\begin{abstract}
Introduction: Healthy the card serves as a tool for monitoring the motion of growth.

The population in this study were a number of mothers in the Posyandu Dadali III, Tugu, Cimanggis, Depok.

Objective: This research was conducted to find out the relationship between mother's knowledge about healthy card with nutritional status of children.

Method: The design of this study was cross-sectional with 83 respondents were used as samples. Univariate analysis used frequency and proportion. The bivariate analysis in this study used The ChiSquare Test with p-value $<0.05$

Results: The results of this study obtained p-value of 0.021 which means that there is a relationship between mother's knowledge about healthy card with nutritional status of children.

Conclusion: The results of this study obtained pvalue of 0.021 which means that there is a relationship between mother's knowledge about healthy card with nutritional status of children.
\end{abstract}

Keywords: children, healthy card, knowledge, nutritional status

Pada masa ini paling sering menderita kekurangan gizi dan gizi buruk. ${ }^{2}$ Kebutuhan gizi untuk anak pada awal masa kehidupannya merupakan hal yang sangat penting. Kekurangan gizi dapat memberikan konsekuensi buruk yang tak terelakkan, dimana manifestasi terburuk dapat menyebabkan kematian. ${ }^{3}$ 
Salah satu faktor yang mempengaruhi status gizi balita adalah pengetahuan, sikap dan perilaku ibu tentang gizi dalam memilih dan memberikan makanan. Pengetahuan dan sikap ibu akan mempengaruhi asupan makanan yang ada di dalam keluarga terutama anak. $^{4}$

Pemantauan pertumbuhan balita sangat penting dilakukan untuk mengetahui adanya hambatan pertumbuhan secara dini. Pertumbuhan balita dapat diketahui dari penimbangan setiap bulan sangat diperlukan. ${ }^{5}$ Pemantauan pertumbuhan saat ini merupakan kegiatan utama posyandu yang jumlahnya mencapai lebih dari 260.000 yang tersebar di seluruh Indonesia. Kegiatan pemantauan pertumbuhan di Indonesia telah dilaksanakan sejak tahun 1974 melalui penimbangan bulanan di posyandu dengan menggunakan Kartu Menuju Sehat memuat kurva pertumbuhan normal anak berdasarkan indeks antropometri berat badan menurut umur.

Proses pemantauan perkembangan anak balita di posyandu bertujuan untuk mengetahui keadaan kesehatan dan memantau gizinya melalui penimbangan berat badan setiap bulannya dan dilakukan pencatatan dalam kartu menuju sehat. Hal itu dilakukan agar bisa diketahui apakah anak tersebut tumbuh normal sesuai pertumbuhannya atau tidak dan mengetahui lebih awal (deteksi dini) terjadinya gangguan pertumbuhan. ${ }^{6}$ Kegiatan pemantauan berat badan balita di posyandu adalah salah satu kegiatan utama program perbaikan gizi yang menitikberatkan pada upaya pencegahan

dan peningkatan keadaan gizi anak. Studi pendahuluan di Posyandu Dadali III pada bulan Januari 2019 masih banyak ibuibu yang belum memanfaatkan KMS balita baik dalam pemantauan pertumbuhan maupun kesehatan balita. Dari 48 balita yang memiliki KMS, hanya 16 ibu balita yang memanfaatkan KMS $(33,3 \%)$. Umumnya ibu-ibu balita di Posyandu Dadali III hanya membawa KMS setiap bulan ke posyandu untuk dicatat hasilnya saja oleh petugas kesehatan dan kemudian di simpan dan tidak diperhatikan dan dimanfaatkan hasil yang telah dicatatkan di KMS tersebut. Hal ini juga berkaitan dengan kurangnya pengetahuan ibu balita tentang manfaat dan pentingnya. Selain itu, hasil dari wawancara dengan 10 ibu di posyandu Dadali III, 4 diantaranya belum memahami tentang pemberian gizi seimbang pada balita, 3 diantaranya sikap ibu dalam pemilihan makanan untuk balitanya masih belum benar mereka juga disibukkan dengan pekerjaan rumah sehingga waktu untuk memperhatikan makanan balitanya lebih sedikit, 3 diantaranya tindakan ibu dalam penyajian makannya belum benar. Hasil dari wawancara dengan ketua posyandu dan kader mengatakan bahwa sebagian dari ibu balita jarang berkunjung dan menimbangkan balitanya ke posyandu karena balitanya sudah selesai diimunisasikan dan ibu lebih mementingkan pekerjaan di rumah. Tujuan penelitian ini adalah untuk meningkatkan pengetahuan ibu terkait KMS dan status gizi balitanya

\section{Metode}

Penelitian ini merupakan penelitian kuantitatif dengan menggunakan desain deskriptif korelasi, menggunakan pendekatan cross-sectional. Penelitian ini untuk mengetahui hubungan antar variabel independen dan dependen di identifikasi pada satu satuan waktu. ${ }^{7}$ Analisa bivariat bertujuan untuk mengetahui hubungan antara variabel independen dan dependen melalui uji Chi Square. Peneliti menggunakan uji Chi Square untuk penelitian ini dikarenakan semua data variabel independen dan variabel dependen penelitian ini berjenis kategorik.

Lokasi yang dijadikan tempat penelitian adalah balai warga RW 08 yaitu Posandu Dadali III Kelurahan Tugu Kecamatan Cimanggis Depok. Peneliti memilih Posyandu Dadali III. Rentang waktu yang digunakan yaitu pada saat pembuatan proposal sampai pelaksanaan penelitian dan sidang hasil. Penelitian ini dilakukan pada bulan April sampai Juni 2019. Populasi dalam penelitian ini adalah ibu yang memiliki anak balita yang dibawa ke Posyandu di wilayah RW 8 Kelurahan Tugu Kecamatan Cimanggis berjumlah 83 ibu yang memiliki balita usia 15 tahun. Instrumen yang digunakan adalah kuesioner.

\section{Hasil}




\section{Analisis Univariat}

Tabel 1. Distribusi Frekuensi Berdasarkan Pengetahuan Ibu di Posyandu Dadali III Tugu $(\mathrm{n}=83)$

\begin{tabular}{lll}
\hline $\begin{array}{c}\text { Karakterisrik } \\
\text { Responden } \\
\text { (Status Gizi) }\end{array}$ & Frekuensi & Presentase \\
\hline Baik & 21 & 25,3 \\
Kurang Baik & 62 & 76,7 \\
\hline Total & 83 & 100 \\
\hline
\end{tabular}

Tabel 1, menunjukkan bahwa dari 83 responden didapatkan hasil distribusi frekuensi berdasarkan pengeathuan ibu sebanyak 23 responden $(27,7 \%)$ memiliki pengetahuan yang kurang dan sebanyak 60 responden $(72,3 \%)$ memiliki pengetahuan yang baik. Hasil penelitian yang dilakukan didapatkan mayoritas pengetahuan responden sudah cukup memahami isi dari kartu menuju sehat.
Tabel 2. Distribusi Frekuensi berdasarkan Status Gizi Balita di Posyandu Dadali III Tugu $(\mathrm{n}=83)$

\begin{tabular}{lll}
\hline $\begin{array}{c}\text { Karakteristik } \\
\text { Responden } \\
\text { (Pengetahuan) }\end{array}$ & Frekuensi & $\begin{array}{c}\text { Presen- } \\
\text { tase }\end{array}$ \\
\hline Baik & 23 & 27,7 \\
Kurang Baik & 60 & 72,3 \\
\hline Total & 83 & 100 \\
\hline
\end{tabular}

Tabel 2, menunjukkan bahwa dari 83 responden didapatkan hasil distribusi frekuensi berdasarkan status gizi balita sebanyak 21 responden $(25,3 \%)$ mengalami malnutrusi dan sebanyak 62 responden (74,7\%) memiliki pengetahuan yang baik. Hasil penelitian yang dilakukan didapatkan mayoritas status gizi baik.

\section{Analisis Bivariat}

Tabel 3. Analisis Hubungan Pengetahuan Ibu tentang Kartu Menuju Sehat dengan Status Gizi Balita di Posyandu Dadali III Tugu (n=83)

\begin{tabular}{|c|c|c|c|c|c|c|c|c|}
\hline \multirow{3}{*}{$\begin{array}{l}\text { Penge- } \\
\text { tahuan }\end{array}$} & \multicolumn{4}{|c|}{ Status Gzi } & \multicolumn{2}{|c|}{ Total } & \multirow{2}{*}{$\begin{array}{c}\text { OR } \\
(95 \% \mathrm{CI}) \\
\end{array}$} & \multirow{3}{*}{ P Valuc } \\
\hline & \multicolumn{2}{|c|}{ Baik } & \multicolumn{2}{|c|}{ Kurang } & & & & \\
\hline & $\mathbf{n}$ & $\%$ & $\mathbf{n}$ & $\%$ & $\mathbf{n}$ & $\%$ & & \\
\hline Baik & 49 & 81,7 & 11 & 18,3 & 60 & 100 & & \\
\hline $\begin{array}{c}\text { Kurang } \\
\text { Baik }\end{array}$ & 13 & 54,5 & 10 & 45,5 & 23 & 100 & $\begin{array}{r}3,712 \\
(1,281- \\
10,756)\end{array}$ & 0,021 \\
\hline Total & 62 & 74,4 & 21 & 25,6 & 83 & 100 & & \\
\hline
\end{tabular}

\section{Pembahasan}

Tabel 3 diatas, hasil analisis terhadap pengetahuan ibu tentang kartu menuju sehat dengan status gizi balita bahwa dari $60 \mathrm{ibu}$ menunjukkan pengetahuan baik dalam pemahaman tentang kartu menuju sehat, sebanyak $49 \mathrm{ibu}(81,7 \%)$ memiliki status gizi yang baik dan yang memiliki status gizi malnutrisi sebanyak $11 \mathrm{ibu}(18,3 \%)$. Sedangkan dari 23 ibu yang menunjukkan pengetahuan kurang baik dalam pemahaman tentang kartu menuju sehat sebanyak $13 \mathrm{ibu}$ $(54,5 \%)$ memiliki status gizi yang baik dan sebanyak $10 \mathrm{ibu}(45,5 \%)$. Berdasarkan hasil uji statistik didapatkan nilai p Value $=0,021$ $<0,05$, sehingga Ho ditolak. Hasil ini menunjukkan bahwa ada hubungan yang signifikan antara pengetahuan ibu tentang kartu menuju sehat dengan status gizi balita. Data hasil 
penelitian diperoleh juga nilai $\mathrm{OR}=3,712$, yang sama dengan $\mathrm{OR}>1$, menunjukan bahwa ibu yang pengetahuannya kurang baik mempunyai peluang 3,712 kali lebih tinggi untuk balitanya mengalami status gizi yang tidak normal dibandingkan ibu dengan tingkat pengetahuan yang baik.

Pengetahuan juga merupakan hasil dari tahu dan inti terjadi setelah orang melakukan penginderaan terhadap objek tertentu melalui panca indra manusia yakni : indra penglihatan, pendengaran, penciuman, rasa dan raba. ${ }^{9}$ Pengetahuan ibu itu sendiri dimaksudkan sebagai sesuatu atau beberapa hal yang diketahui oleh ibu sebagai pengasuh diantaranya mengenai fungsi dari kartu menuju sehat, serta interpretasi dari kartu menuju sehat sebagai pedoman untuk mengetahui status gizi balitanya.

Hasil penelitian ini sejalan dengan penelitian di di Wilayah RW V Kelurahan Kalipancur Kecamatan Ngaliyan Kota Semarang, ada hubungan antara tingkat pengetahuan ibu tentang KMS dengan pertumbuhan balita. ${ }^{10}$ Pada penelitian yang dilakukan diketahui bahwa dari sejumlah ibu yang tingkat pengetahuannya tentang KMS kurang, sebagian besar balitanya tidak mengalami kenaikan berat badan. Pertumbuhan balita dipengaruhi oleh beberapa faktor yang merupakan suatu rangkaian tidak dapat dipisahkan dan saling terkait satu sama lain. Diantaranya beberapa faktor yang mempengaruhi pertumbuhan balita, faktor pengetahuan ibu tentang KMS memiliki peran yang cukup dominan. Hal ini dibuktikan dapat diketahui dengan melihat hasil $P$ value $=0,007$.

Hasil penelitian yang dilakukan di Puskesmas Paal Merah I Kota Jambi menunjukan bahwa responden yang memiliki pengetahuan baik dan memiliki persepsi negative tidak sebanding dengan status gizi balita yang dialami oleh balita tersebut. ${ }^{11}$ Hasil didapatkan responden dengan pengetahuan cukup ada yang status gizinya kurang. Hal ini disebabkan oleh berbagai faktor misalnya dari segi persepsi sebagian ibu masih mempercayai adat istiadat setempat misalnya ibu masih mempercayai tentang pantangan makanan yang tidak boleh dikonsusmsi padahal makanan tersebut baik bagi balitanya sehingga asupan gizi anaknya tidak terpenuhi. Hasil uji yang chi-square yang dilakukan diperoleh nilai $p$-value $0,606(\mathrm{p}<0,05)$ maka dapat disimpulkan tidak ada hubungan antara pengetahuan dengan status gizi balita.

Faktor-faktor yang mempengaruhi pengetahuan yaitu pendidikan, media atau informasi, sosial budaya ekonomi, lingkungan, dan usia. Maka, pendidikan adalah suatu usaha untuk mengembangkan kepribadian dan kemampuan didalam dan diluar sekolah berlangsung seumur hidup dan usia mempengaruhi daya tangkap dan pola pikir seseorang. Semakin bertambah usia maka akan semakin bertambah daya tangkap dan pola pikirnya, sehingga pengetahuan yang dimiliki semakin baik. ${ }^{12}$

Berdasarkan hasil penelitian yang dilakukan di wilayah Posyandu Dadali III, masih ditemukan ibu dengan pengetahuan baik akan tetapi balitanya mengalami gizi kurang. Hal ini terjadi karena pengetahuan dipengaruhi oleh beberapa faktor, seperti : Usia, Pendidikan Paparan Informasi, Sosial ekonomi (Pendapatan), Hubungan Sosial, serta Pengalaman. Pendidikan adalah suatu usaha untuk mengembangkan kepribadian dan kemampuan didalam dan diluar sekolah berlangsung seumur hidup dan usia mempengaruhi daya tangkap dan pola pikir seseorang. ${ }^{13}$ Semakin bertambah usia maka akan semakin bertambah daya tangkap dan pola pikirnya, sehingga pengetahuan yang dimiliki semakin baik. Pengetahuan yang baik ditunjang dengan pengalaman yang dimiliki akan mendukung dalam proses implementasinya. ${ }^{14} \mathrm{Da}-$ lam proses implementasi dari pengetahuan yang dimiliki oleh ibu dalam mengasuh anak juga diperlukan perekonomian yang baik. ${ }^{15}$

Ibu yang tinggal diwilayah Posyadu Dadali III masih merupakan ibu yang baru memiliki anak, hal ini jadi salah satu faktor yang sangat berpengaruh karena ibu belum memiliki pengalaman mengasuh anak 
sebelumnya. Sedikitnya pengalaman ibu dalam mengasuh anak membuat ibu belum bisa memodifikasi hal-hal yang berkaitan dengan anak. ${ }^{16}$ Misalnya, ibu masih menganggap pemberian makanan untuk memenuhi kebutuhan gizi bahan makanan yang diperlukan harganya mahal. Karena pendapatan ekonomi yang dimiliki rendah maka ibu memberikan makanan anak tidak sesuai dengan porsi dan takaran gizi yang cukup. Pengetahuan ibu juga perlu ditingkatkan, mulai dari pemahaman dalam membaca hasil KMS, tingkat status gizi anak, cara-cara dalam mengasuh dan merawat anak, serta pengetahuan dalam pemberian makanan anak mengenai takaran makanan, komposisi serta jenis makanan yang dapat memenuhu kebutuhan zat gizi anak. ${ }^{17}$ Dengan demikian, ibu harus bisa memodifikasi cara mengasuh dalam proses implementasinya agar status gizi keluarga khususnya anak tetap tercukupi dan terpenuhi.

\section{Kesimpulan}

Setelah dilakukan pembahasan terhadap hasil penelitian sebagaimana yang telah dijelaskan dibab sebelumnya, maka dapat dibuat kesimpulan bahwa gambaran pengetahuan ibu di Posyandu Dadali III Tugu, Sebagian besar ibu didaerah tersebut memiliki pengetahuan baik tentang Kartu Menuju sehat. Begitupun didapatkan hasil gambaran status gizi balita di Posyandu Dadali III Tugu bahwa status gizi balita yang baik. Berdasarkan keterangan diatas maka dapat disimpulkan ada hubungan yang bermakna antara pengetahuan ibu tentang kartu menuju sehat dengan status gizi balita.

\section{Daftar Pustaka}

1. Sutomo B, Anggraini Y. Menu Sehat Alami untuk Batita dan Balita. Jakarta Selatan: Demedia; 2010.

2. Notoatmodjo S. Metodologi Penelitian Kesehatan. Jakarta: PT Rineka Cipta; 2010.

3. Lastanto. Analisis Faktor Yang Mempengaruhi Kejadian Balita Gizi Kurang Di Wilayah Kerja Puskesmas Cebongan, Surakarta: STIKES Kusuma Husada. http://www.digilib.stikeskusu-

mahusada.ac.id, Diakses pada tanggal 28 Desember 2019.

4. Departemen Kesehatan RI. Profil Kesehatan Indonesia, Jakarta: Depkes RI; 2012 (25 Juni 2019) tersedia di halaman : http://www.depkes.go.id

5. Riset Kesehatan Dasar (Riskesdas). Badan Penelitian dan Pengembangan Kesehatan Kementerian RI tahun 2013; 2013 (19 Juni 2015) dari http://www.depkes.go.id.

6. Departemen Kesehatan RI. Profil Kesehatan Indonesia, Jakarta: Depkes RI; 2013 diakses dari http://www.depkes.go.id

7. Dharma K. Metedologi Penelitian Keperawatan, Jakarta: CV Trans Info Media; 2011.

8. Hastono P. Analisis Data Kesehatan, Jakarta : Rineka Cipta; 2013.

9. Notoatmodjo S. Promosi Kesehatan Dan Perilaku Kesehatan, Jakarta: Rineka Cipta; 2015.

10. Meiranny A. Pengetahuan Ibu tentang Kartu Menuju Sehat (KMS) Mempengaruhi Pertumbuhan Balita. SMART Kebidanan Sekolah Tinggi Ilmu Kesehatan (STIKes) Karya Husada Semarang, 2017: 4(2), 9-17

11. Putri K M. Hubungan Pengetahuan dan Persepsi dengan Status Gizi Balita di Puskesmas Paal Merah I Kota Jambi Tahun 2017. Kebidanan Potekkes Semarang,2018: 7(15), 1-9.

12. Chaidez, V, et al 2011, Toddler-feeding practices among Mexican American mothers, A qualitative study, Appetite, 56(3), 629- 32 .

13. Hockenberry, M J \& Wilson, D 2011, Wong's Nursing Care of Infants and Children, 9e. St. Louis: Mosby.

14. Murashima, M, dkk. Maternal parenting behaviors during childhood relate to weight status and fruit and vegetable intake of college students. Journal of Nutrition Education and Behavior. 2012: 44(6), 556-63.

15. Mardiana 2009, Hubungan Perilaku dengan Status Gizi Balita di Puskesmas Tanjung Beringin Kecamatan Hinai Kabupaten, Skripsi Program S1 Ilmu kesehatan Masyarakat Fakultas Kesehatan Masyarakt Universitas Sumatera Utara, http://www. jukeunila.com.

16. Sutomo, B \& Anggraini, Y 2010, Menu Sehat Alami untuk Batita dan Balita, Jakarta Selatan: Demedia. 
17. Ulistyaningsih 2011, Gizi Untuk Kesehatan Ibu Dan Anak, Jakarta: Graha Ilmu. 